\title{
Erratum to: A comparison of methods to estimate seasonal phenological development from $\mathrm{BBCH}$ scale recording
}

\author{
Christine Cornelius • Hannes Petermeier • \\ Nicole Estrella • Annette Menzel
}

Published online: 20 June 2014

(C) ISB 2014

Erratum to: Int J Biometeorol, Volume 55, Issue 6, pp. 867-877

DOI 10.1007/s00484-011-0421-x

The purpose of the paper was to present and compare four different methods to analyze phenological data of populations recorded on a refined $\mathrm{BBCH}$ scale in order to estimate onset dates for each phenological stage.

The OLR method described is one way to determine those onset dates. Compared to the other methods investigated, the OLR method is based on the frequency distribution over time which includes the entire progression of plants in the model and not only the progression of a single stage.

However, the equation that describes the OLR model (Eq. 4) was wrong in the original version of the manuscript:

$\log \left(\frac{P}{1-P}\right)=\alpha+\sum \beta_{i} \cdot x_{i}$
$P=\mathrm{P}\left(\mathrm{Y}_{\mathrm{i}}=1 \mid \mathrm{x}_{\mathrm{i}}\right)$ is the probability and $\mathrm{Y}$ is the ordinal response variable, $\alpha$ is the intercept parameter, $\beta_{\mathrm{i}}$ the slope parameters and $\mathrm{x}_{\mathrm{i}}$ the explanatory variable (here time).

Thus, please consider the corrected equation, which reads as follows:

$\log \left(\frac{p}{1-p}\right)=\alpha_{i}+\beta \cdot t$

where $p=P(Y \geq i \mid t)$ is the cumulative probability that the observed phenological phase $\mathrm{Y}$ (coded as ordinal integer) is above a certain phase $i$ given the time $t, \alpha_{i}$ are the intercept parameters for each phase $i, \beta$ the slope parameter for time $t$ (here: day of year).

The online version of the original article can be found at http://dx.doi.org/ 10.1007/s00484-011-0421-x.

C. Cornelius $(\bowtie) \cdot N$. Estrella $\cdot$ A. Menzel

Chair of Ecoclimatology, Technische Universität München,

Hans-Carl-von-Carlowitz-Platz 2, 85354 Freising, Germany

e-mail: cornelius@wzw.tum.de

H. Petermeier

Fachgebiet Biostatistik, Technische Universität München,

Maximus-von-Imhof-Forum 2, 85354 Freising, Germany 